\title{
Invariant natural killer T cells developing in the human fetus accumulate and mature in the small intestine
}

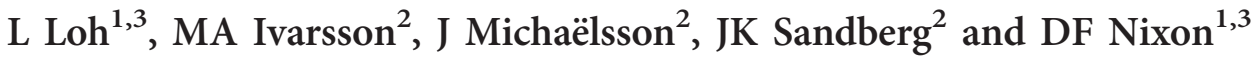

Invariant natural killer T (iNKT) cells are CD1d-restricted immunoregulatory lymphocytes that share characteristics of both the innate and adaptive immune systems. Although it has been reported that iNKT cells are present in the human fetal thymus, it is currently unknown how they distribute, differentiate, and function in fetal peripheral lymphoid and nonlymphoid organs. Here, we show that functional human fetal iNKT cells develop and differentiate in a tissue-specific manner during the second trimester. Fetal iNKT cells accumulated in the small intestine, where they gained a mature phenotype and mounted robust interferon (IFN)- $\gamma$ responses. In contrast, iNKT cells in the spleen and mesenteric lymph nodes were less frequently detected, less differentiated, mounted poor IFN- $\gamma$ responses, but proliferated vigorously upon stimulation with $\alpha$-galactosylceramide. These data demonstrate that fetal iNKT cells can differentiate and acquire potent effector functions in utero before the establishment of the commensal microflora.

\section{INTRODUCTION}

Invariant natural killer $\mathrm{T}$ (iNKT) cells are a subset of evolutionarily conserved innate-like $\mathrm{T}$ cells that recognize antigen presented by CD1d. They are defined by their invariant T-cell receptor, ${ }^{1}$ containing a V $\alpha 24 \mathrm{~J} \alpha \mathrm{Q}$ rearrangement preferentially paired with V $\beta 11$ in humans, and V $\alpha 14 \mathrm{~J} \alpha 18$ paired with V $\beta 8.2$ in mice. The representation of iNKT cells is highly variable between individuals, and in human peripheral blood they range from $0.001 \%$ up to $>1 \%$ of the T-cell compartment. An important characteristic of iNKT cells is their capacity to rapidly produce cytokines, such as interferon (IFN)- $\gamma$, interleukin (IL)-4, and tumor necrosis factor (TNF)- $\alpha$, upon recognition of glycolipid antigens presented by CD1d. iNKT cells are highly reactive to CD1d presenting the sphingolipid $\alpha$-galactosylceramide $\left(\alpha\right.$-GalCer), ${ }^{1}$ microbial glycolipids from different species, e.g., Borrelia burgdorferi ${ }^{2}$ and Sphingomonas $s p p,{ }^{2}$ and endogenous mammalian $\beta$-linked glycolipids, including $\beta$-glucosylceramide ( $\beta$-GlcCer). ${ }^{3}$ Most recently, a prominent member of the gut microbiome, Bacteroides spp, has been found to produce an $\alpha$-linked sphingolipid structurally related $\alpha$-GalCer, which similarly modulates NKT function. ${ }^{4}$ This diverse reactivity provides iNKT cells with immune modulating capacities, and they have important roles in the resolution or pathology of microbial and viral infections, cancers, and autoimmune diseases. ${ }^{5-7}$

iNKT cells develop in the thymus from precursor CD4+ $\mathrm{CD} 8+$ thymocytes, and are positively selected by CD1d molecules expressed on CD4 + CD8 + thymocytes..$^{8-11} \mathrm{CD} 1 \mathrm{~d}$ is highly expressed in the thymus, ${ }^{12}$ and the endogenous CD1d ligand $\beta$-GlcCer is readily detected in mouse thymus, ${ }^{3}$ indicating that $\beta$-GlcCer presented by CD1d could be involved in iNKT cell selection. Whereas iNKT cells are present in the human fetal thymus at higher frequencies at the start of the second trimester, their representation gradually declines with gestational age, and they are present at very low frequency in the post-natal thymus. This indicates that a relatively large part of the thymic iNKT cell output occurs during early fetal development. ${ }^{12,13}$

\footnotetext{
${ }^{1}$ Division of Experimental Medicine, Department of Medicine, University of California San Francisco, San Francisco, California, USA and ${ }^{2}$ Center for Infectious Medicine, Department of Medicine, Karolinska Institutet, Karolinska University Hospital Huddinge, Stockholm, Sweden. Correspondence: L Loh or DF Nixon (Ioh!@unimelb.edu.au or dnixon@gwu.edu)

${ }^{3}$ Current affiliation: Department of Microbiology and Immunology, University of Melbourne, at the Peter Doherty Institute for Infection and Immunity, Victoria 3010, Australia (L.L.); Department of Microbiology, Immunology and Tropical Medicine, George Washington University, Washington, DC 20037, USA (D.F.N.).
}

Received 24 October 2013; accepted 4 February 2014; published online 19 March 2014. doi:10.1038/mi.2014.13 
In the fetal thymus, iNKT cells are largely $\mathrm{CD} 4+$, and only a small fraction express CD161. ${ }^{12,14}$ In full-term cord blood, iNKT cells remain largely CD $4+$, and approximately 50\% express CD161. In addition, a majority of the full-term cord blood iNKT cells express CCR7 and CD62L, but interestingly lack expression of CD45RA (normally associated with a naïve T-cell phenotype). ${ }^{14,15}$ In contrast to fetal thymus and term cord blood, a majority of the iNKT cells in adult blood lack expression of CD4, are almost uniformly CD161 +, and only a small proportion express CD62L or CCR7. This indicates that iNKT cell differentiation is characterized by gradual loss of CD4 expression, increased expression of CD161, and loss of CD62L and CCR7. ${ }^{16-18}$ This model of iNKT cell differentiation has also been corroborated in longitudinal studies of cord blood transplantations, where the first iNKT cells to develop are largely $\mathrm{CD} 4{ }^{+} \mathrm{CD} 161{ }^{-} \mathrm{CCR} 7{ }^{+} \mathrm{CD} 62 \mathrm{~L}^{+}$. These cells subsequently loose expression of CD4, CD62L, and CCR7, and acquire expression of CD161, as well as CD56 and CD94/ NKG2A. ${ }^{15,19}$ The differentiation of iNKT cells after cord blood transplantation is also associated with increased production of IFN- $\gamma$ and IL-4, indicating that the phenotypic differentiation is also coupled to functional maturation. ${ }^{15}$

During normal pregnancies, the fetus is believed to be developing in a sterile environment. In mice, the presence of commensal bacteria early after birth controls the accumulation of iNKT cells in the colon, and decreases susceptibility to experimentally induced mucosal inflammation. ${ }^{20}$ In addition, iNKT cells in germ-free mice are less differentiated, and respond poorly upon antigen stimulation, ${ }^{21}$ indicating that commensal bacteria can drive the differentiation and functional maturation of iNKT cells. However, it remains unknown to what extent the microflora affects human iNKT cell development and function.

Although human iNKT cells are detected in the fetal thymus early during gestation, it remains unknown when, and to what extent they migrate to peripheral lymphoid and non-lymphoid organs, whether fetal iNKT cells differentiate in the peripheral organs, and if they are functional. Here, we show that human fetal iNKT cells are present in the small intestine, lung, spleen, and mesenteric lymph nodes (MLNs) during the second trimester. There was a striking accumulation of iNKT cells in the small intestine, which contained an approximately fivefold higher frequency of iNKT cells compared with other organs. Small intestinal iNKT cells exhibited characteristics of differentiated cells, with more frequent expression of CD161, IFN- $\gamma$ production, and a lower proliferative capacity in response to $\alpha$-GalCer stimulation. Conversely, the iNKT cells in lymph nodes and spleen exhibited a less differentiated phenotype, with lower frequency of CD161 expression, poor IFN- $\gamma$ production, and higher proliferative capacity. Taken together, our data suggest that differentiation and functional maturation of human iNKT cells can occur in the absence of a commensal flora in the small intestine, and that intestinal iNKT cells have the potential to have an immunoregulatory role in the developing human fetus, as well as directly after birth.

\section{RESULTS \\ iNKT cells are present in human fetal lymphoid and non-lymphoid peripheral tissues}

We have previously shown that iNKT cells can be detected at low frequency in the human fetal thymus. ${ }^{12}$ To investigate which other tissues contained iNKT cells in the developing fetus, we analyzed mononuclear cell suspensions from fetal tissues between gestational weeks 16 and 22 by flow cytometry. iNKT cells were defined as CD1d tetramer + (loaded with the $\alpha$-GalCer analog PBS57) CD ${ }^{+}{ }^{+}$TCR V $\alpha 24^{+}$cells (Figure 1 a and Supplementary Figure $\mathbf{S 1}$ online). We could detect iNKT cells in fetal lung, small intestine, spleen, MLNs, and less consistently in fetal liver (Figure 1a, b). Minimal background staining was observed with the unloaded CD1d tetramer, demonstrating the specificity of the staining (Supplementary Figure S2). Strikingly, in the small intestine, iNKT cells comprised up to 5.4\% (average $1.21 \%$ ) of the total T cells, whereas iNKT cells in lung, spleen, and MLN comprised less than $0.5 \%$ (average $0.19 \%, 0.27 \%$, and $0.16 \%$, respectively) of the total T cells (Figure $1 \mathbf{b}$ ). As a reference, iNKT cells in adult peripheral blood mononuclear cells (PBMCs) on average made up $0.21 \%$ of the total T cells (Figure $\mathbf{1 b}$ ). The frequency of iNKT cells increased with gestational age in the small intestine (Figure 1c) and spleen (Figure 1d), whereas no such correlation was observed in MLNs (data not shown). It should, however, be noted that the minimum age of MLN was gestational week 18 , because of the scarcity of these structures at earlier gestational ages.

\section{CD1d is expressed in the fetal small intestinal architecture}

Given the high frequency of iNKT cells in the fetal small intestine, we investigated whether CD1d was expressed in this tissue. CD1d was distinctly expressed in the epithelium of the small intestine (Figure 2b, c). Interestingly, CD1d was also localized between epithelial cells, clustered around the tips of the villi. CD1d staining was also observed in the Peyer's patches of the small intestine (Figure 2a). No background staining was observed from the IgG1 isotype control section (Figure 2d-f).

\section{Fetal iNKT cells can differentiate in utero}

Given the distinct accumulation of iNKT cells in the small intestine, compared with spleen, lymph node, and lung, we next analyzed whether there was also a distinct pattern of differentiation associated with the different tissues. iNKT cell differentiation is characterized by a transition from $\mathrm{CD}^{+}{ }^{+}$to $\mathrm{CD}^{-}$cells, in addition to increased expression of CD161 and lower expression of CD62L and CCR7. iNKT cells in the spleen and $\mathrm{MLN}$ were almost exclusively $\mathrm{CD} 4{ }^{+} \mathrm{CD} 8{ }^{-}$(Figure 3a), indicative of an immature phenotype. In contrast, a significantly smaller proportion of the iNKT cells in the small intestine were $\mathrm{CD} 4{ }^{+} \mathrm{CD} 8{ }^{-}$compared with fetal spleen and MLN (Figure 3a), indicating that a small fraction of the iNKT cells in the small intestine had differentiated into CD4 ${ }^{-}$ phenotypes. However, fetal iNKT cells in all organs investigated displayed a less differentiated phenotype compared with adult iNKT cells, which were predominantly $\mathrm{CD} 4{ }^{-} \mathrm{CD} 8{ }^{-}$or $\mathrm{CD} 4{ }^{-}$ $\mathrm{CD}^{+}$(Figure 3a). To further address differences between iNKT cells in the intestine, spleen, and MLN, we analyzed the 
a
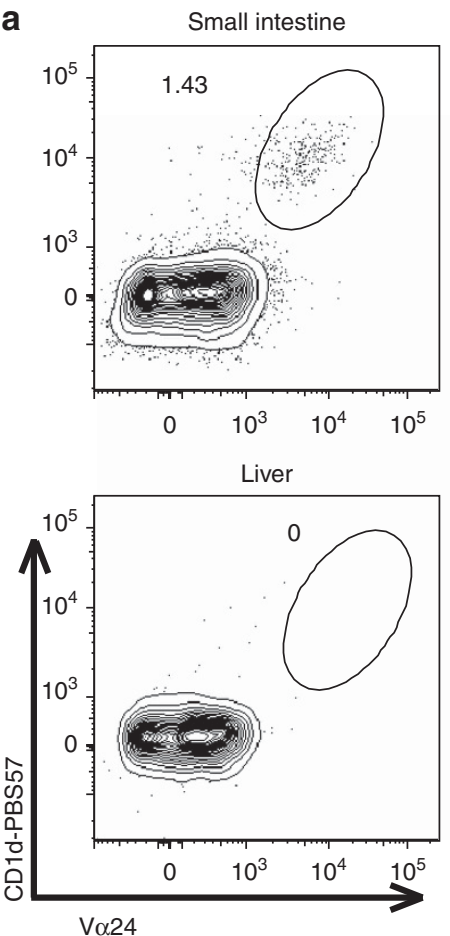

b

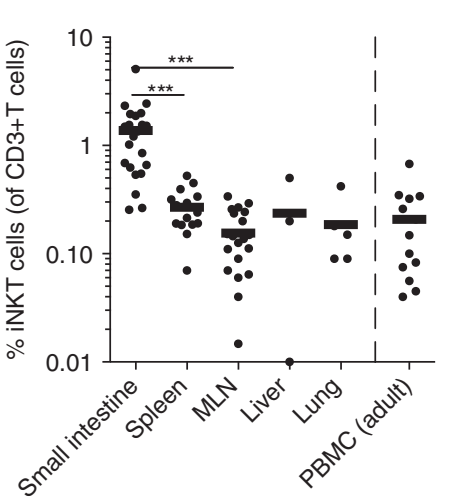

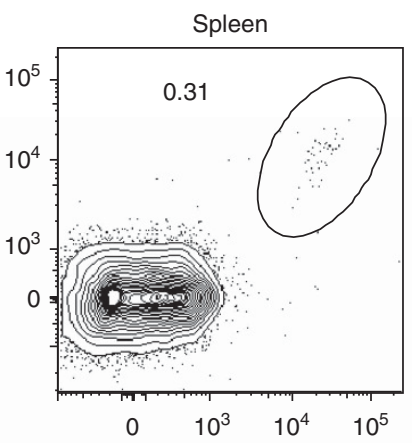
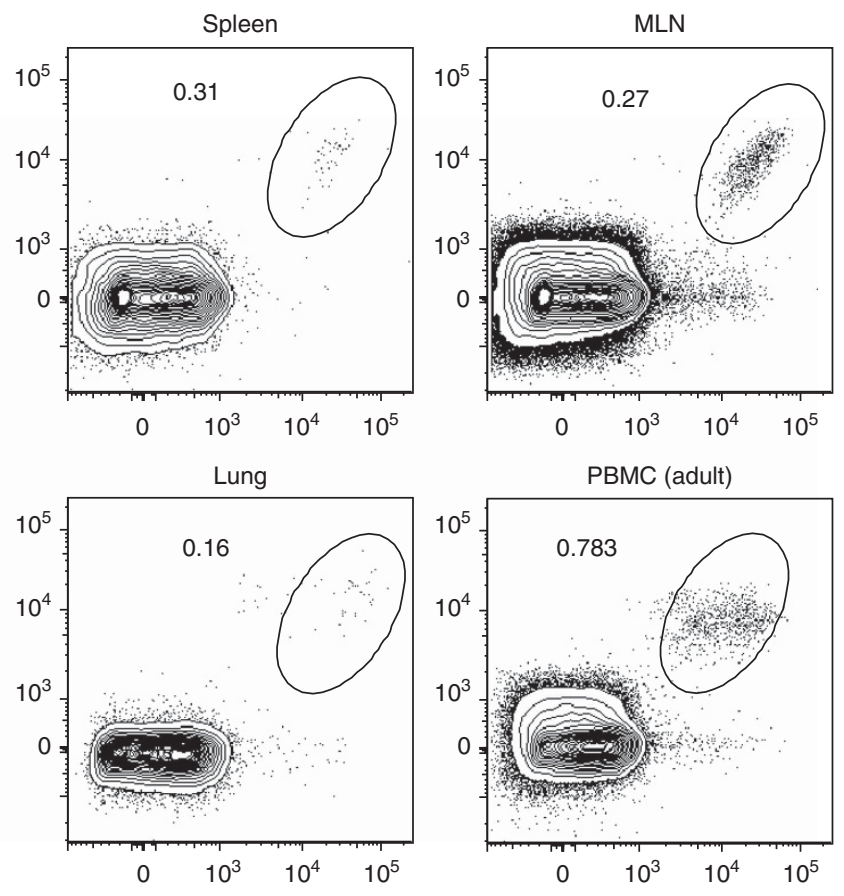

C

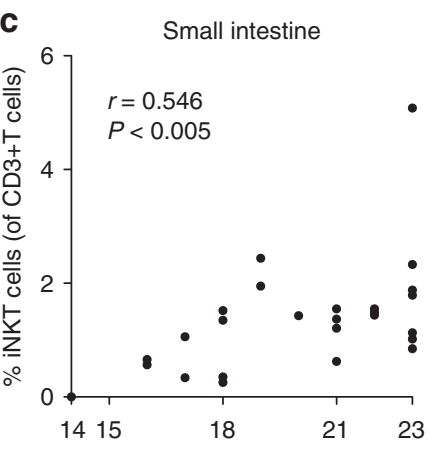

Gestational week

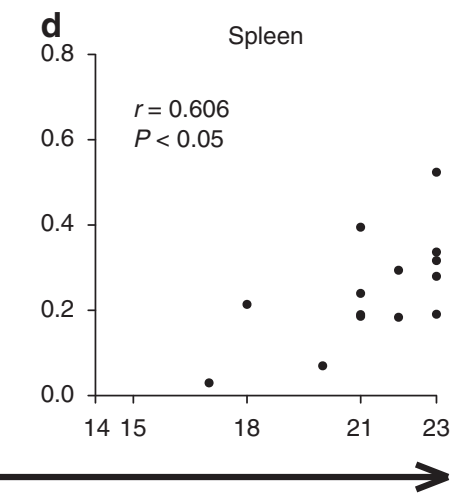

Figure 1 The invariant natural killer T (iNKT) cells in different fetal organs. (a) The frequency of iNKT cells (CD1d-PBS57 tetramer + ) in fetal organs from a representative donor was analyzed by flow cytometry. iNKT cell frequencies are shown as a percentage of live CD3 + cells.

Adult peripheral blood mononuclear cells (PBMCs) are shown as a positive control. (b) Fetal iNKT cells are found at a higher frequency in the small intestine. Gestational ages between weeks 18 and 23 are shown, the minimum age for mesenteric lymph node (MLN) acquisition was week 18. One-way analysis of variance analysis between fetal small intestine, spleen, and MLN. iNKT cell frequency versus gestational age in the small intestine (c) and spleen (d). Spearman rank correlation shown.

expression of a range of markers associated with iNKT cell differentiation. Interestingly, a much smaller fraction of iNKT cells in the small intestine expressed CD161 and CD45RO, compared with iNKT cells from the spleen and MLN (Figure 3b, c). Furthermore, iNKT cells in the small intestine lacked expression of CD62L and CCR7, whereas these receptors were expressed by a large proportion of the iNKT cells in the spleen and MLN, thus indicating that the iNKT cells in the small intestine were more differentiated than those in lymphoid tissues (Figure $\mathbf{3 b}$ and $\mathbf{c}$ ). In addition, a fraction of iNKT cells in the small intestine also expressed CD56, as well as NKG2A, expression of these proteins was undetectable on
iNKT cells in fetal spleen and MLN (Figure $\mathbf{3 b}$ and $\mathbf{c}$ and Supplementary Figure S3B). Whereas iNKT cells from all fetal tissues and adult blood uniformly expressed CD127 (IL-7R $\alpha$ ) and CD122 (IL-2R $\beta$ ) (Figure 3b), a much larger fraction of the fetal iNKT cells expressed CD25 (IL-2R $\alpha$ ) compared with adult blood iNKT cells (Figure $\mathbf{3 b}$ and $\mathbf{c}$ ), indicating that fetal iNKT cells might be more responsive to low doses of IL-2. CD25 was, however, expressed at an intermediate level compared with fetal regulatory $\mathrm{T}$ cells, which express high levels of CD25 (Supplementary Figure S3). ${ }^{22}$ To further dissect the differentiation of iNKT cells in different tissues, we analyzed the co-expression of CD4 and CD161, as well as the co-expression 


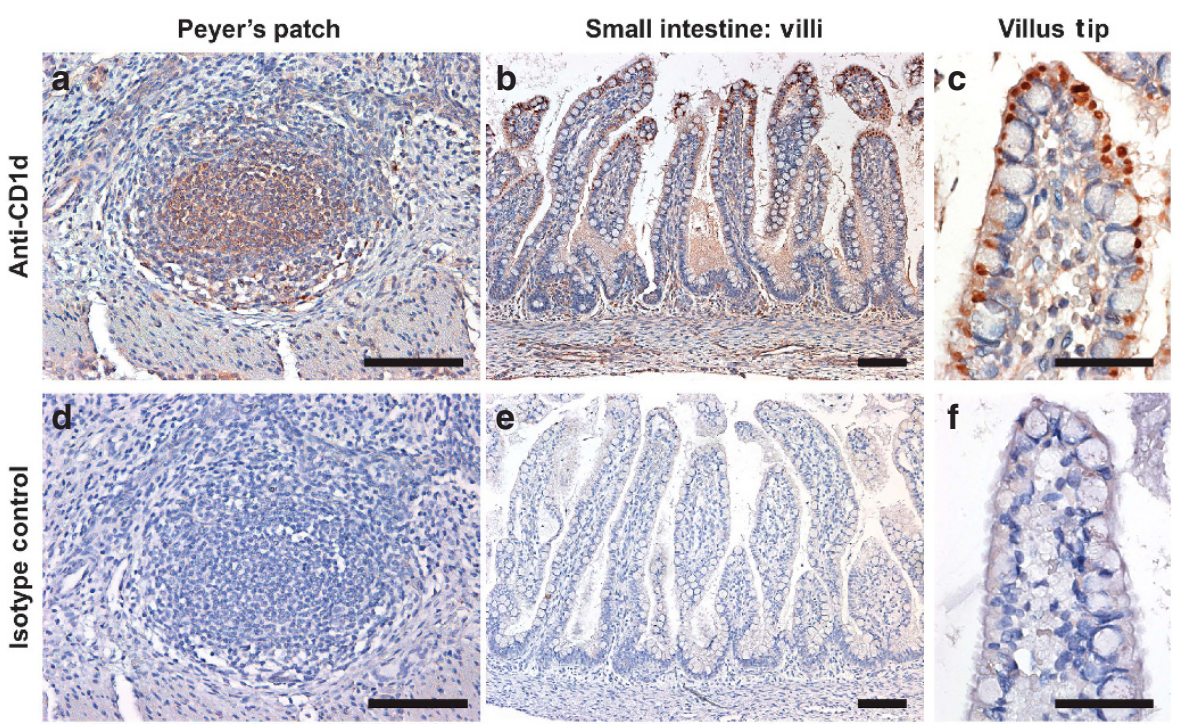

Figure 2 Analysis of CD1d in the fetal small intestine by immunohistochemistry. CD1d staining (NOR3.2 clone) of formaldehyde-fixed, paraffinembedded fetal small intestinal sections. (a) Peyer's patch. (b) Small intestine: villi. (c) Villus tip. (d-f) IgG1 isotype control antibody. Scale bars (a, b, d and e) represent $100 \mu \mathrm{m} ;(\mathbf{c}, \mathbf{f}) 50 \mu \mathrm{m}$.

of CD45RO and CD62L. The majority of CD4-iNKT cells from all fetal tissues and adult blood were $\mathrm{CD}_{161}{ }^{+}$(Figure 4a). However, fetal iNKT cells from the small intestine had higher frequencies of $\mathrm{CD} 4^{-} \mathrm{CD} 161^{+}$iNKT cells, as well as $\mathrm{CD} 4^{+}$ CD161 ${ }^{+}$iNKT cells compared with iNKT cells from fetal spleen and MLN (Figure 4a). Furthermore, iNKT cells from the small intestine were uniformly $\mathrm{CD} 45 \mathrm{RO}^{+} \mathrm{CD}_{62 \mathrm{~L}^{-}}$, whereas iNKT cells from the spleen and MLN displayed transitional profiles of CD45RO and CD62L expression, with distinct subsets of $\mathrm{CD} 45 \mathrm{RO}^{-} \mathrm{CD}^{-} \mathrm{L}^{+}$(naïve), $\mathrm{CD} 45 \mathrm{RO}^{-} \mathrm{CD}^{-} \mathrm{L}^{-}$ and $\mathrm{CD} 45 \mathrm{RO}^{+} \mathrm{CD}^{-} 2 \mathrm{~L}^{-}$iNKT cells (Figure $4 \mathbf{b}$, upper panels). Interestingly, the small intestine also contained a higher proportion of $\mathrm{CD}_{4} 5 \mathrm{RO}^{+} \mathrm{CD}^{2} 2 \mathrm{~L}^{-}$conventional $\mathrm{T}$ cells, indicating that $\mathrm{T}$ cells in this tissue are more differentiated in general (Figure $\mathbf{4 b}$, lower panels). Taken together, our data show that iNKT cells with a differentiated phenotype accumulate in the small intestine, indicating that iNKT cells can differentiate in utero in the absence of commensal microflora.

\section{Fetal iNKT cells in the small intestines have gained the capacity to produce IFN- $\gamma$}

Adult iNKT cells in human peripheral blood rapidly produce large amounts of cytokines, including TNF- $\alpha$ and IFN- $\gamma$ after stimulation with $\alpha$-GalCer. However, it remains unknown whether fetal iNKT cells in peripheral organs are functionally mature. Germ-free mice, lacking a commensal microflora, have been shown to have a diminished production of TNF- $\alpha$ and IFN- $\gamma$ compared with specific pathogen-free mice after stimulation with $\alpha$-GalCer. ${ }^{21}$ This opens the possibility that human fetal iNKT cells could be similarly functionally immature as a consequence of lack of priming from a commensal microflora. To assess the cytokine-producing potential of fetal iNKT cells, mononuclear cell suspensions from the spleen, MLN, and small intestine were stimulated with
$\alpha$-GalCer followed by staining for IFN- $\gamma$ and TNF- $\alpha$. Minimal background cytokine production in the absence of stimulation was observed (data not shown). Stimulation with $\alpha$-GalCer resulted in a strong TNF- $\alpha$ production, comparable to that of the adult PBMC iNKT cells (Figure 5a). When comparing the three fetal tissues, iNKT cells in the small intestine and spleen expressed significantly higher levels of TNF- $\alpha$ compared with those from MLN $(P \leq 0.05$, Figure 5b). A much higher frequency of the iNKT cells in the small intestine produced IFN- $\gamma$ compared with those in spleen and MLN, and the frequency of IFN- $\gamma^{+}$iNKT cells in the small intestine approached the levels seen in adult blood iNKT cells (Figure 5a, b). Given that the IFN- $\gamma$ responses to $\alpha$-GalCer stimulation were lower in the lymphoid organs, we sought to examine whether IFN- $\gamma$ production by iNKT cells from spleen and MLN would be more robust in response to TCR-independent activation mechanisms. We therefore stimulated mononuclear cells from fetal spleen, MLN, and small intestine, as well as adult blood, with phorbol myristate acetate/ionomycin. iNKT cells in the small intestine produced IFN- $\gamma$ much more frequently than those in the spleen and MLN (Supplementary Figure S4). Together, these data indicate that small intestinal fetal iNKT cells have gained a mature effector function, including IFN- $\gamma$ production.

\section{High-proliferative capacity of fetal iNKT cells in lymphoid tissues}

Given the differential ability of fetal iNKT cells from diverse tissues to produce cytokines, we next sought to investigate the proliferative potential of these cells. To assess the proliferative capacity, mononuclear cell suspensions were labeled with cell tracer violet and cultured with $\alpha$-GalCer and IL-2 (Figure 6). After 6-7 days of culture in the presence of $\alpha$-GalCer and IL-2, the vast majority of iNKT cells from all fetal tissues assessed had 


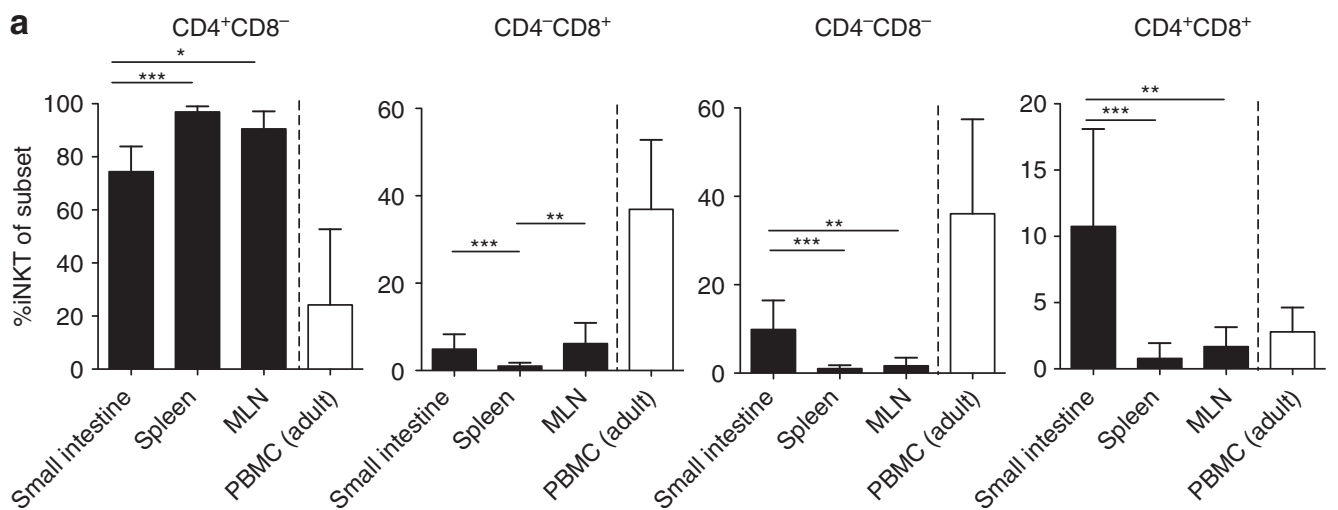

b

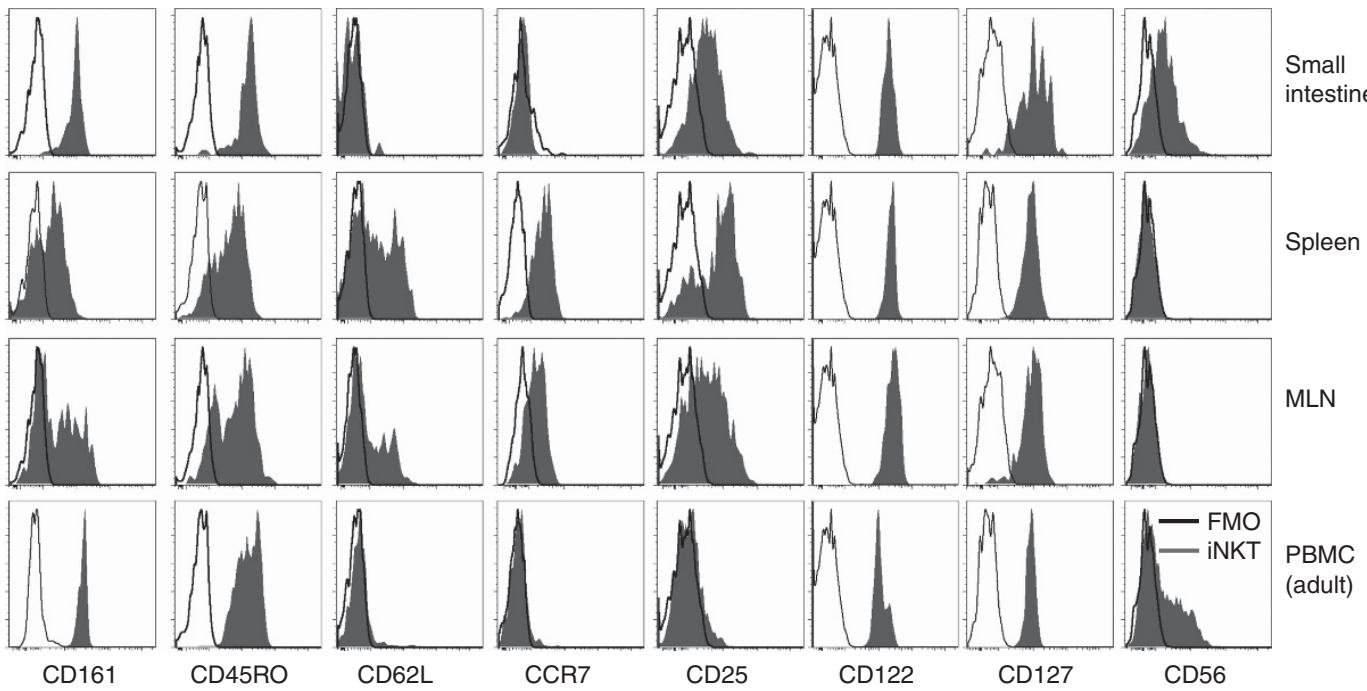

C
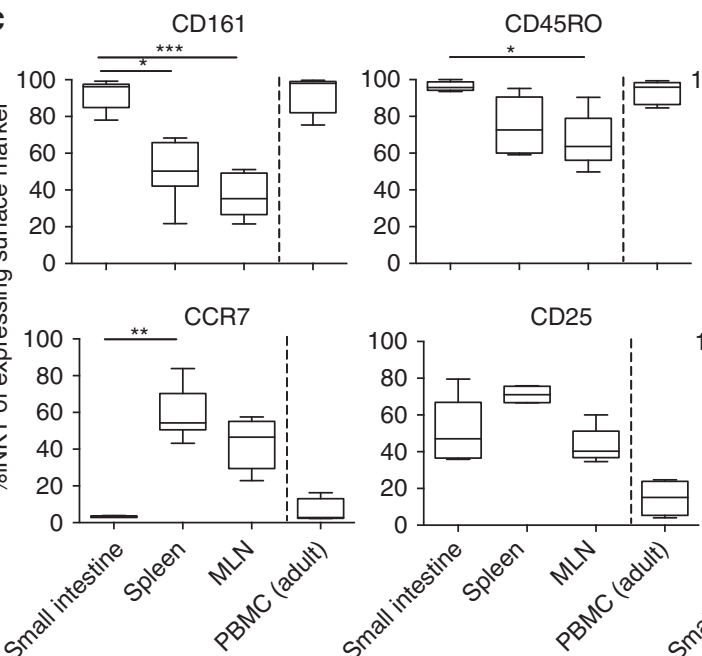

CD62L

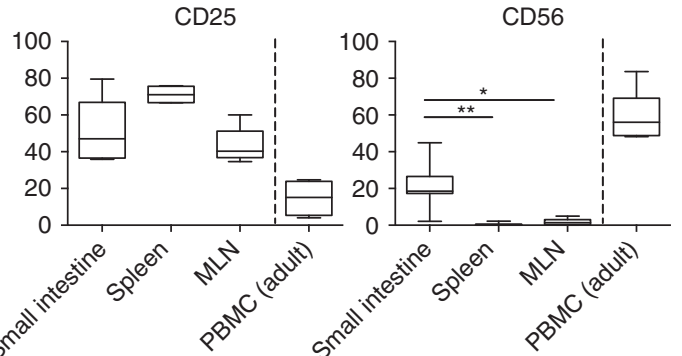

Figure 3 The maturation phenotype of small intestinal invariant natural killer T (iNKT) cells is distinct from their lymphoid counterparts. (a) CD4 and CD8 expression on iNKT cells were analyzed by flow cytometry. Frequencies are shown as a percentage of iNKT cells. Adult peripheral blood mononuclear cells (PBMCs) were included as a control. ${ }^{* \star *} P \leq 0.001,{ }^{\star \star} P \leq 0.01, P^{\star} \leq 0.05$; one-way analysis of variance analysis between fetal small intestine, spleen, and mesenteric lymph node (MLN). (b) Markers of lymphocyte maturation were analyzed by flow cytometry on fetal iNKT cells (shaded histograms). The open histograms represent fluorescence minus one (FMO) controls. (c) Frequency of iNKT cells expressing selected cell surface markers represented as box plots. Box and whisker plot show median, interquartile range, and the 25th to 75th percentile. ${ }^{\star \star \star} P \leq 0.001,{ }^{\star \star} P \leq 0.01, P^{\star} \leq 0.05$. $n=4-8$.

proliferated, as evidenced by dilution of cell tracer violet (Figure 6a, upper panel). We also observed some proliferation of fetal, but not adult, non-iNKT cells (Figure 6a, lower panel).
However, the presence of $\alpha$-GalCer did not alter the proliferation of fetal non-iNKT cells, indicating that IL-2 alone largely drove this proliferation. Interestingly, in the 

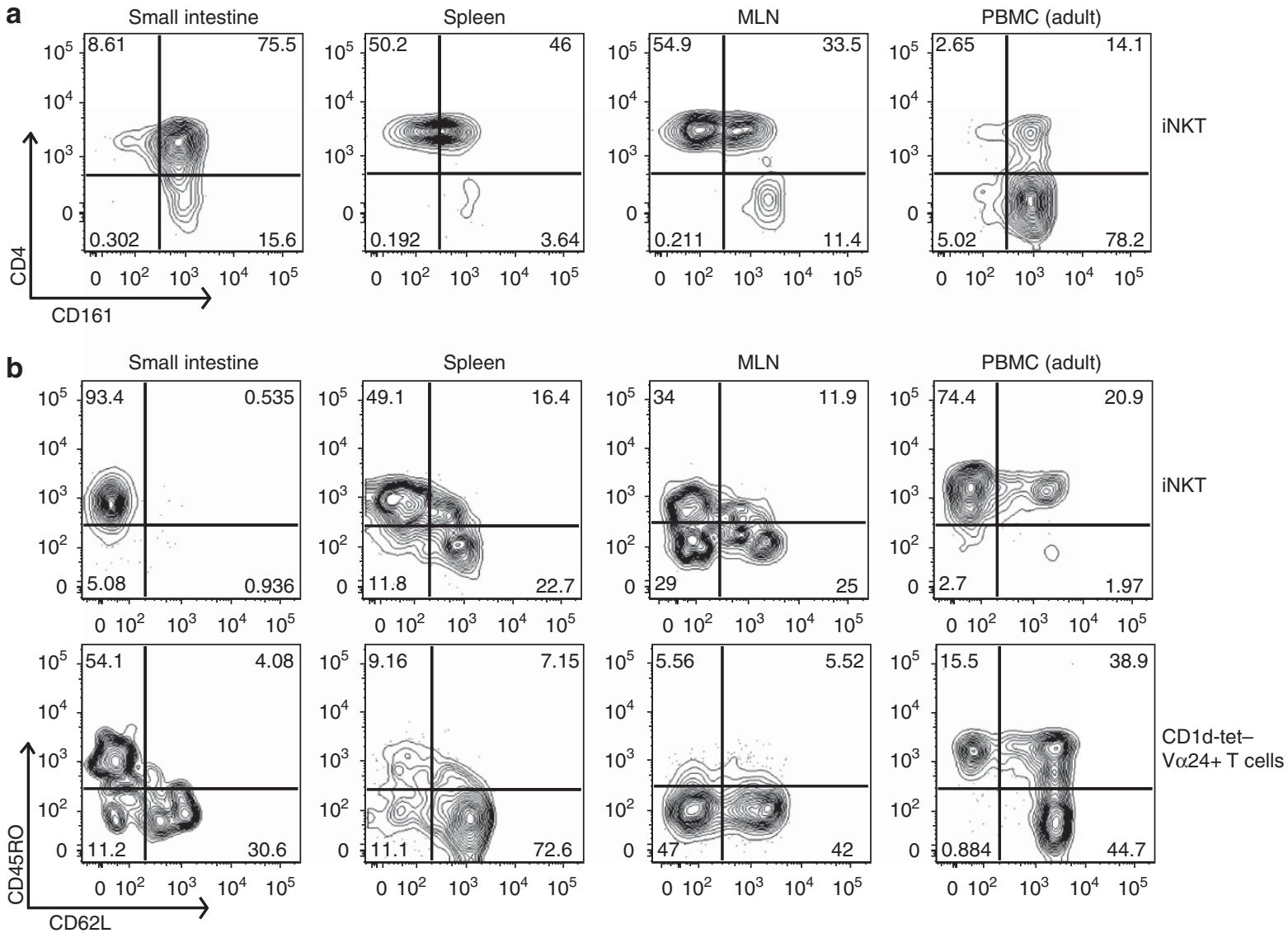

Figure 4 Invariant natural killer T (iNKT) cells in the fetal small intestine have a differentiated phenotype. (a) CD4-iNKT cells in the fetus are exclusively $\mathrm{CD}_{161}{ }^{+}$. (b) Transitional stages of memory are present in the fetal spleen and mesenteric lymph node (MLN) iNKT population (upper panel). Fetal noniNKT cells $\left(\mathrm{CD} 1 \mathrm{~d}\right.$-tet ${ }^{-} \mathrm{V} \alpha 24^{+}$), lower panel. Representative fluorescence-activated cell sorting (FACS) plots are shown, $n \geq 4$.

small intestine, approximately $50 \%$ of iNKT cells underwent proliferation in response to IL-2 alone (Figure 6a, upper panel, black histogram), whereas a substantially smaller fraction of iNKT cells from spleen responded to IL-2 alone. Stimulation of cell trace-labeled MLN with IL-2 alone was not available, however, unlabeled cells from the MLN were analyzed with IL-2 stimulation alone. When compared with culture in the presence of $\alpha$-GalCer and IL-2, small intestinal iNKT cells from IL-2 culture alone were CD1dtet ${ }^{\text {hi }}$ and $\mathrm{CD} 3^{\text {hi }}$ (Supplementary Figure S5), indicating that their proliferation was not mediated by CD1d/TCR-induced activation. This was also apparent in the spleen, MLN, and adult PBMCs (Supplementary Figure S5). Although iNKT cells from all tissues proliferated extensively, as analyzed by the dilution of the cell trace dye to background levels, it remained possible that the iNKT cells proliferated beyond the complete dilution of the cell tracker dye, leading to differences in the proliferative response between different tissues. When analyzing the frequency of iNKT cells from the different tissues after 6-7 days of culture in IL-2 and $\alpha$ GalCer, there was a marked increase of CD1d-tetramer ${ }^{+}$cells from spleen and MLN (>10-fold) compared with small intestine ( $<5$-fold; Figure $\mathbf{6 b}-\mathbf{d}$ ), indicating that iNKT cells in the spleen and MLN had a greater ability to proliferate compared with those from the small intestine. It, however, remained possible that the lower degree of iNKT cell expansion in the small intestine was due to a greater expansion of other $\mathrm{T}$ cells in this tissue, thus partially masking the expansion of iNKT cells. This in part can be seen with the increase in the frequency of $\mathrm{V} \alpha 24^{+}$non-iNKT in the presence of IL-2 ${ }^{+/-} \alpha$-GalCer at days 6-7 (Figure 6b, middle and lower panels). Conversely, frequencies of $\mathrm{V} \alpha 24^{+}$non-iNKT cells in the spleen, MLN, and adult PBMCs remain similar to those at day 0 (Figure 6b). Furthermore, the non-iNKT $\mathrm{CD} 3{ }^{+}$population in the small intestine undergoes a greater number of divisions compared with the spleen (Supplementary Figure S6). Alternatively, iNKT cells in the small intestine may undergo apoptosis or downregulate CD3/TCR to a greater degree than those in the spleen and MLN, and thus confounding the analysis. However, in all organs with culture in the presence of $\alpha$-GalCer, the expression of CD3/TCR was similar (Supplementary Figure S5, lower panel), indicating that the lower level of expansion was not solely due to a selective downregulation of the TCR on iNKT cells from small intestine. In addition, we could detect an increased frequency of CD1d-tetramer ${ }^{+}$cells among the dead cells from small intestine compared with spleen (Supplementary Figure S7). A detectable population of dead cells was 

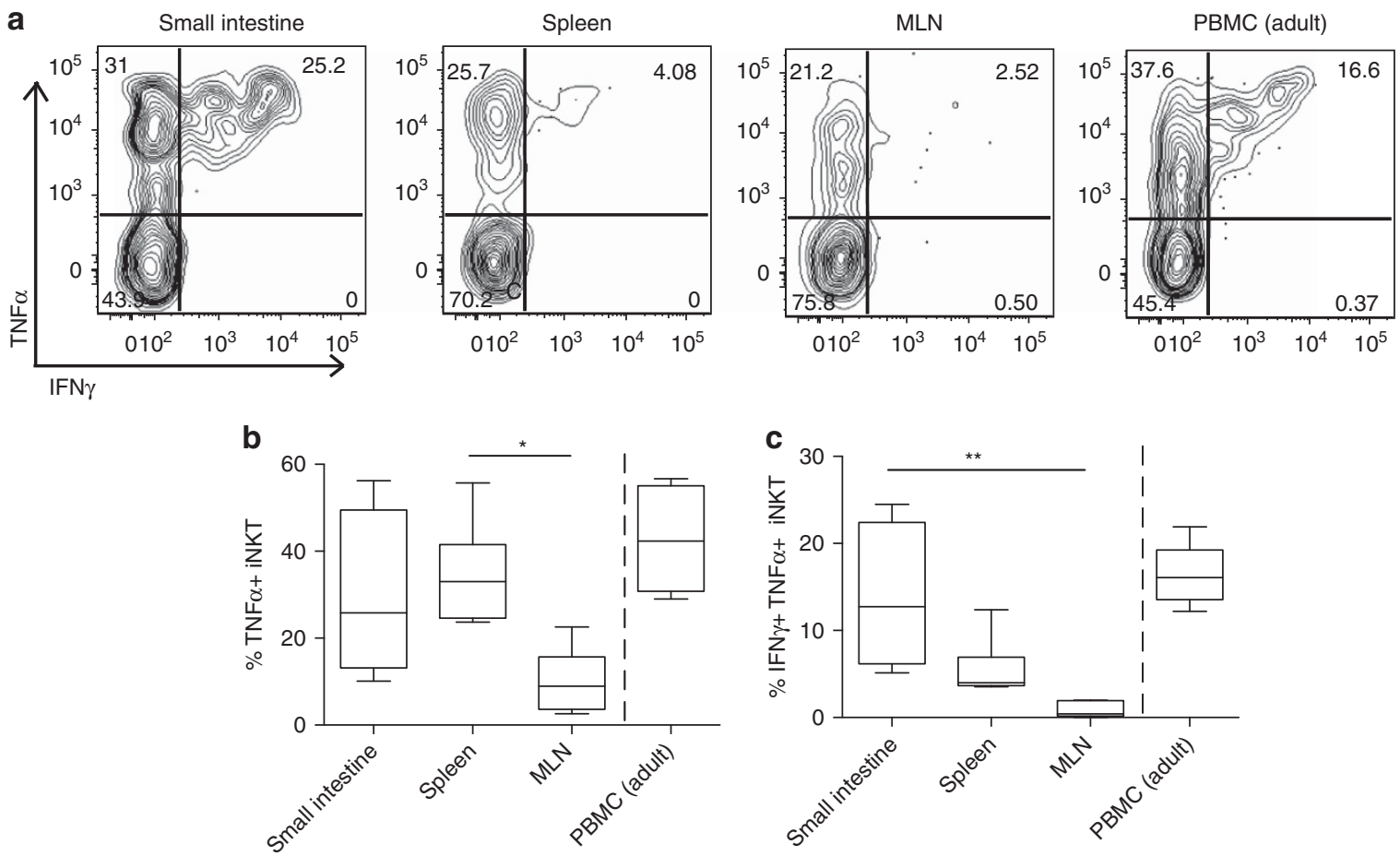

Figure 5 Cytokine production by fetal invariant natural killer T (iNKT) cells. (a) Mononuclear cells in fetal tissues and adult peripheral blood mononuclear cells (PBMCs) were stimulated with $\alpha$-GalCer for $8 \mathrm{~h}$ in the presence of brefeldin A and analyzed by intracellular cytokine staining. (a) The proportion of cytokine-producing fetal iNKT cells producing interferon (IFN)- $\gamma$ and tumor necrosis factor (TNF)- $\alpha$ are shown in contour plot ( $\geq 100$ iNKT events were analyzed), representative fluorescence-activated cell sorting (FACS) plots are shown. (b) The percentage of TNF- $\alpha+$ and (c) IFN- $\gamma^{+}$TNF $\alpha^{+}$iNKT cells are presented as box plots, $n=4-6$. Box and whisker plot show median, interquartile range, and the 25 th to 75 th percentile. ${ }^{* \star} P \leq 0.01$, ${ }^{\star} P \leq 0.05$.

present in the MLN, however, the frequency of live MLN iNKT was greater. Finally, by comparing the frequency of iNKT cells in small intestine, spleen, and MLN after stimulation with IL-2 alone and IL-2 ${ }^{+} \alpha$-GalCer, the increase in iNKT cell frequency was greater in both the spleen and MLN compared with the small intestine (Figure 6b), indicating that the iNKT cells in the small intestine indeed have a lower proliferative capacity. After day 7 of $\alpha$-GalCer culture, increased CD161 expression was observed in splenic iNKTs (Supplementary Figure S8A), indicating maturation after culture with exogenous antigens. In the spleen and MLN, the composition of iNKT cells with respect to expression of $\mathrm{CD} 4$ and CD8 remained largely unaltered, indicating that all subsets had proliferated (Supplementary Figure S8B and C). After 6-7 days of stimulation with $\alpha$-GalCer and IL-2, the frequency of $\mathrm{CD} 4{ }^{+} \mathrm{CD} 8{ }^{-}$iNKT cells was increased in the small intestine, whereas the frequency of $\mathrm{CD} 4{ }^{+} \mathrm{CD} 8^{+}$and $\mathrm{CD} 4{ }^{-} \mathrm{CD} 8^{-}$iNKT cells decreased, indicating that $\mathrm{CD} 4{ }^{+} \mathrm{CD} 8^{-}$iNKT cells in the intestine had a proliferative advantage (Supplementary Figure S8B, gray circles). These observations suggest that fetal iNKT cells require glycolipid antigens to proliferate, and that iNKT cells in the spleen and MLN have a higher capacity to proliferate than their small intestinal counterparts.

\section{DISCUSSION}

In mice, iNKT cells develop in the thymus and exit as an immature subset. ${ }^{23}$ Likewise, studies of human cord blood, maternal decidua, and fetal thymic organ cultures have indicated that full iNKT cell maturation occurs in the periphery. ${ }^{12,13,24-26}$ However, it remains unknown when and to what extent fetal iNKT cells migrate to peripheral lymphoid and non-lymphoid organs, whether fetal iNKT cells differentiate in the peripheral organs, and if they are functional. Here, we show that human fetal iNKT cells are found in peripheral non-lymphoid and lymphoid organs before birth, and that the frequency of iNKT cells in the spleen and small intestine increases with gestational age. Strikingly, there was a pronounced accumulation of iNKT cells in the human fetal small intestine that exhibited a differentiated and functionally mature profile, as compared with iNKT cells found in the secondary lymphoid tissues, spleen, and MLN.

The consistent detection of iNKT cells in spleen, MLN, and small intestine indicates that these organs are among the first sites where iNKT cells traffic after leaving the thymus. In contrast to murine iNKT cells, where enrichment is observed in the liver (up to $50 \%$ of hepatic lymphocytes), ${ }^{27,28}$ we did not detect significant numbers of iNKT cells in human fetal liver. Instead, iNKT cell frequencies were high in the human fetal small intestine, up to $5.4 \%$ of $\mathrm{CD}^{+}$cells at gestational week 23 . In the adult gastrointestinal tract (colon), CD1d-restricted, $\alpha$-GalCer-responsive NKT cells comprise $<0.5 \%$ of lamina propria lymphocytes (reviewed in van Dieren et al. ${ }^{29}$ ). It is unclear whether iNKT cells in the small intestine remain at higher frequencies or retract after birth. However, several 
a
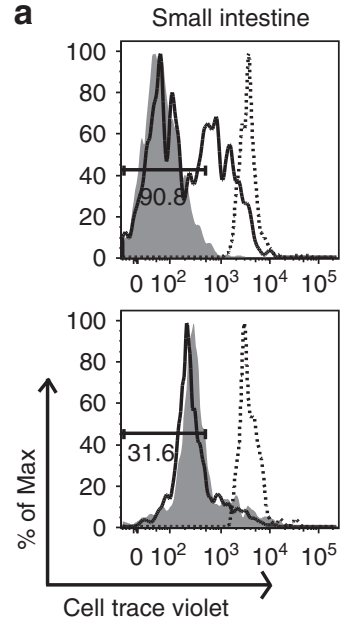

b
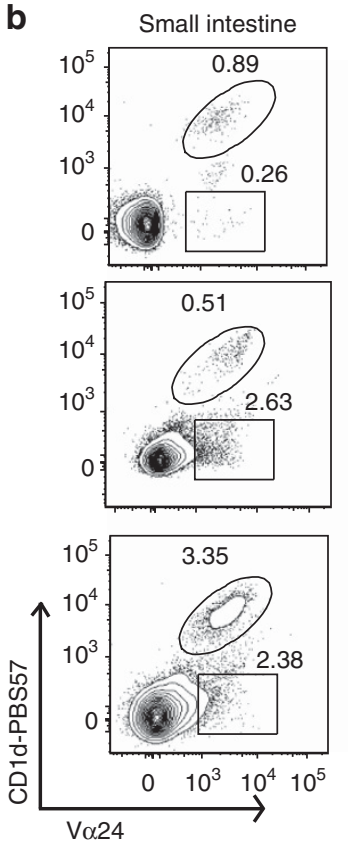

C

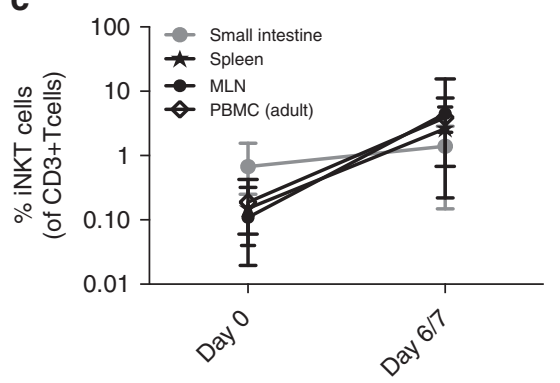

Spleen
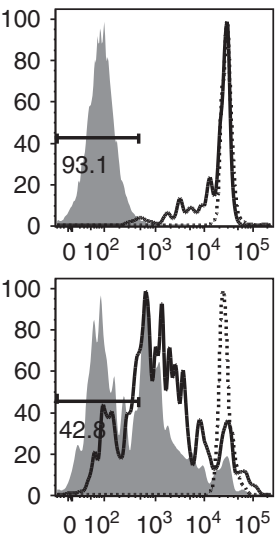

Spleen
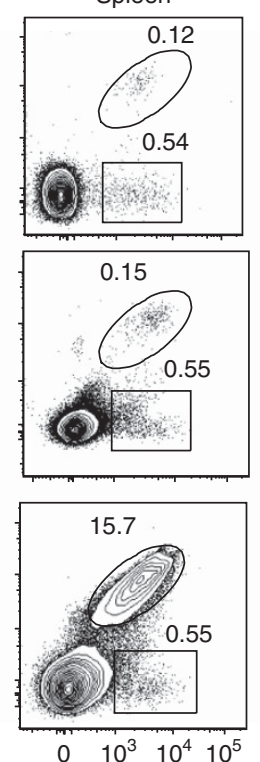

$\begin{array}{llll}0 & 10^{3} & 10^{4} & 10^{5}\end{array}$
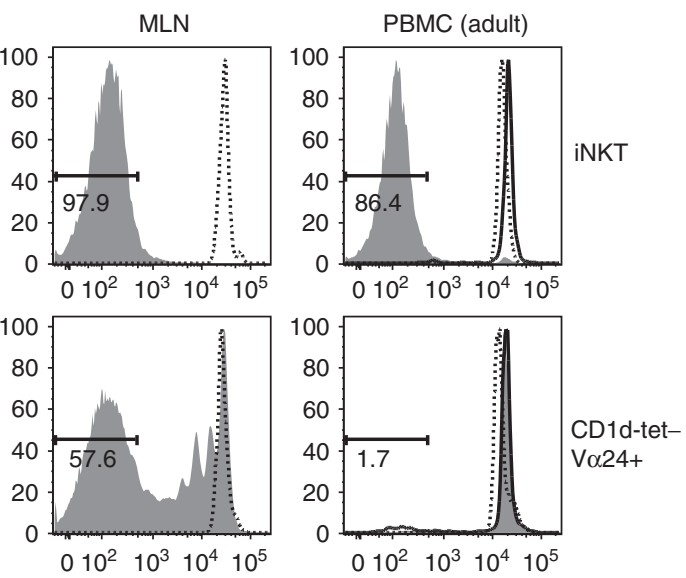
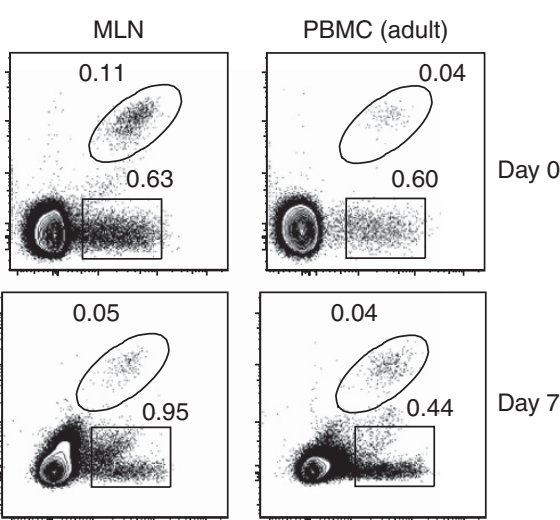

Day 7 IL-2 alone
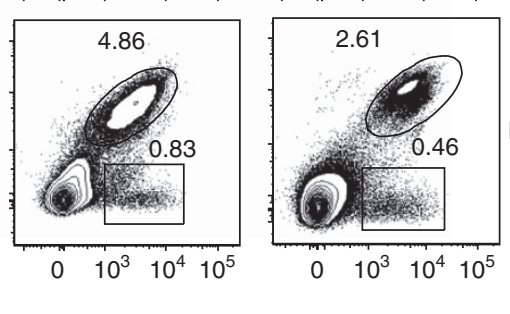

Day 7 IL-2 + $\alpha$-GalCer

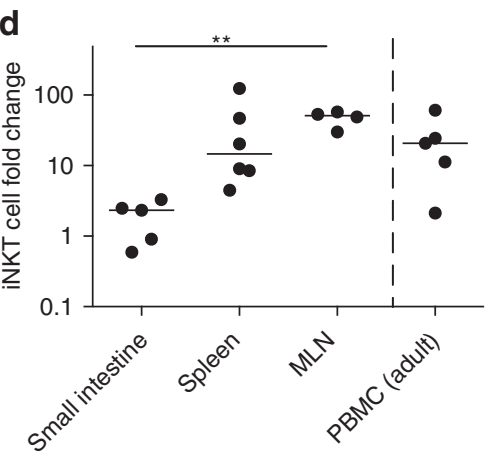

Figure 6 The proliferative capacity of fetal invariant natural killer T (iNKT) cells. Cell trace violet-labeled mononuclear cell suspensions from fetal small intestine, spleen, and adult peripheral blood mononuclear cells (PBMCs) were cultured with $\alpha$-GalCer and interleukin (IL)-2, or IL-2 alone for 6-7 days. (a) Proliferation measured as cell trace violet-dilution in iNKT cells (upper panel) or CD1d-tet-V $\alpha 24+$ non-iNKT cells (lower panel) at day 0 (dotted line), after 7 days of stimulation with $\alpha$-GalCer and IL-2 (gray histogram), or IL-2 alone (open histogram). (b) Example of iNKT frequencies of CD3 ${ }^{+}$ T cells at day 0 (upper panel), and at day 7 in the presence of IL-2 alone (middle panel) or with $\alpha$-GalCer ${ }^{+}$IL-2 (lower panel). (c) Summary of frequencies of iNKT cells in fetal tissues and adult PBMC at day 0 and day $6 / 7$ after stimulation with $\alpha$-GalCer and IL-2. (d) Fold change in iNKT cell frequency (frequency at day 6 or $7 /$ frequency at day 0 ). ${ }^{* *} P \leq 0.01$. 
murine studies have demonstrated the importance of commensal microflora and CD1d in iNKT cell expansions. ${ }^{20,21,30}$ However, our data suggests that human iNKT cells mature and gain function in the small intestine well before birth and the colonization by the normal microflora.

The strikingly mature profile of fetal small intestinal iNKT cells raises the question of what potential roles they may be playing in the human fetal gut. Our study shows that iNKT cells in the small intestine are poised to respond to ligands presented on the non-classical, MHC-class I-like molecule CD1d, to a more robust extent than their lymphoid counterparts. The strong IFN- $\gamma$ responses elicited and lack of lymphoid homing receptors on small intestinal iNKT cells suggests that this cell subset may be playing a potential effector role that is tissue specific. The ability of fetal small intestinal iNKT cells to produce IFN- $\gamma$ in a CD1d-restricted manner may be beneficial in utero or in neonates, given their immature adaptive immune system, ${ }^{31}$ and their potential to be exposed to a range of pathogenic microbes and viruses, including Group B Streptococcus and Streptococcus Pneumoniae. ${ }^{32,33}$ Indeed, recent studies have demonstrated that such bacterial species have been shown to contain glycolipids that activate iNKTs in a CD1d-dependent manner. ${ }^{34,35}$ Speculatively, small intestinal iNKT cells may serve as an innate defense line in the fetus and neonate, and production of $\mathrm{T}_{\mathrm{H}} 1$ cytokines may help activate other effector innate immune cells such as mucosal NK cells and macrophages. ${ }^{36}$ Although iNKT cells are well documented to produce a range of pro- and anti-inflammatory cytokines, only $\mathrm{T}_{\mathrm{H}} 1$ cytokines were investigated in our study. Further analyses of other cytokines after stimulation with $\alpha$-GalCer and additional iNKT cell ligands, e.g., OCH2, $\beta$-GlcCer, GSL- 1 , ${ }^{37}$ may determine whether other iNKT-associated cytokines, such IL-4, IL-22, IL-13, IL-17, are produced by fetal small intestinal and lymphoid iNKT cells.

The question remains as to how this population of peripheral organ iNKT cells matures compared with their lymphoid tissue counterparts. In murine studies, it has been shown that CD1d is critical for iNKT cell maturation. ${ }^{38,39}$ In line with this, we show that CD1d is expressed on the epithelium of the small intestine. It is tempting to speculate that the more mature phenotype of small intestinal iNKT cells could be driven by the presentation of endogenous glycolipids on CD1d. Indeed, recent studies in mice have demonstrated that the endogenous glycolipid, $\beta$ GlcCer, can be isolated from spleen and thymus. ${ }^{3}$ Furthermore, $\beta$-GlcCer has been found to be important in activating iNKT cells via microbial danger signals induced from stimulation of Toll-like receptors. ${ }^{3}$ Such activation in the context of the human fetus raises the question as to whether the fetal environment is completely devoid of microbial products, despite lacking a commensal microflora. Several recent studies have suggested that non-pathogenic bacterial DNA can be detected in the placenta and also in the meconium (the first stool) of neonates. ${ }^{40,41}$ In addition, in mothers who are given probiotic treatment during pregnancy, increased expression of Toll-like receptor-related genes is observed in the meconium of neonates delivered by cesarian sections. ${ }^{42}$ Bacterial products, rather than viable microbes, could thus potentially be contributing to the maturation of iNKT cells in the fetal small intestine.

In addition to microbial products, cytokines such as IL-7 and IL-15 have been shown to be important for the effector maturation of innate cell subsets including both NK and iNKT cells. ${ }^{43-46}$ Indeed, we have previously shown that low doses of IL-7 support the maintenance and maturation of human fetal thymic iNKT cells. ${ }^{12}$ In our current study, human fetal iNKT cells had high expression of IL-7R $\alpha$ (CD127). Furthermore, fetal iNKT cells also highly expressed the IL-2R $\beta$ (CD122) subunit component of the IL-15 receptor. However, further studies would be required to investigate if human fetal lymphoid iNKT cells cultured in the presence of IL-15 resulted in maturation phenotype similar to small intestinal iNKT cells, or if the fetal small intestinal microenvironment has elevated levels of IL-15 compared with lymphoid tissues. Although small intestinal iNKT cells have a mature phenotype and cytokine profile, they did not expand ex vivo to the same extent as the less differentiated iNKT cells from the fetal spleen and MLN. This could be due in part to cell death of small intestinal iNKT cells in culture. In human and murine models, intestinal epithelial/stromal cells provide IL-7 for T cells, ${ }^{47,48}$ hence, the ex vivo culture conditions in the proliferation experiments may not support the survival of these cells. Our data from the proliferation experiments also suggests that small intestinal iNKT cells are different to the lymphoid iNKT cells, given that iNKT cells in the small intestine are responsive to IL-2 stimulation in the absence of $\alpha$-GalCer. In addition, our data also show that conventional $\mathrm{T}$ cells in the small intestine proliferate extensively in the presence of IL-2, and therefore may dilute out the true expansion of iNKT cells in the small intestine in response to $\alpha$-GalCer. Further delaying the addition of IL-2 to ex vivo cultures may ameliorate the background proliferation by conventional $\mathrm{T}$ cells and allow for more accurate assessment of $\alpha$-GalCer-driven expansion. A caveat of our proliferation studies is the lack of data regarding the ex vivo proliferation of cell tracer-labeled fetal iNKTs from the MLN in response to IL-2 alone. Nevertheless, our data with unlabeled cells from the MLN suggests that iNKT cells do not proliferate in the presence of IL-2 alone, given that no difference in iNKT frequency at day $6 / 7$ was observed when compared with day 0 ; however, the extent of conventional $\mathrm{T}$ cells proliferation is unknown. Indeed, from healthy neonatal mice, it is has been shown that IL-2 mRNA transcripts and protein can be isolated from the gut and not from the spleen or lymph nodes, which supports our data regarding the proliferation of conventional $\mathrm{T}$ cells in response to IL-2 alone in the small intestine. ${ }^{49}$ Analyses of mRNA transcripts in situ from human fetal tissue for IL-2 expression would confirm this.

In summary, we have shown that human iNKT cells mature and accumulate in peripheral organs, particularly in the small intestine, during fetal development. This finding further demonstrates that iNKT cells in the human fetal immune system can differentiate and functionally mature before birth, and before the establishment of the normal intestinal microbiota. 


\section{METHODS}

Human subjects and tissues. Heparinized blood was collected from healthy donors after obtaining informed consent. PBMCs were isolated by Ficoll/Pacque ${ }^{\text {Plus }}$ (Amersham Biosciences, Milwaukee, MI) densitygradient centrifugation. Human fetal tissue (small intestine, MLNs, lung, liver, and spleen) were obtained from San Francisco General Hospital Women's Options Clinic (San Francisco, CA) and Advanced Bioscience Resources (Alameda, CA) after obtaining informed consent. Fetal tissues were collected from gestational weeks 16-23.

Tissue preparation. The small intestine was cut into $6 \mathrm{~cm}$ lengths, and the meconium was removed. Small intestinal tissue was then incubated for 20 min in Hanks Buffered Saline Solution $(1 \times$; GIBCO, Carlsbad, CA) containing fungizone $(1 \times$; Invitrogen, Carlsbad, CA $)$ at $37^{\circ} \mathrm{C}$. Small intestine, lung, and liver were subsequently transferred to a cell culture dish, cut into small pieces, incubated for $50 \mathrm{~min}$ at $37^{\circ} \mathrm{C}$ in digestion media (RPMI; GIBCO), $0.25 \mathrm{mg} \mathrm{ml}^{-1}$ Collagenase Type II (Sigma-Aldrich, Steinheim, Germany), fungizone $(1 \times)$, and HEPES (Invitrogen)) with vortexing every $10 \mathrm{~min}$. After the incubation, the cell suspensions were passed through $70-\mu \mathrm{m}$ plastic cell strainers and washed twice with cold complete media containing $10 \%$ fetal calf serum. To obtain single-cell suspensions from the spleen, the tissue was gently pressed through a $70-\mu \mathrm{m}$ cell strainer. The cell suspensions were subsequently centrifuged on a ficoll/paque density gradient to isolate mononuclear cells. MLNs were dissected from intact mesentery using fine pincer forceps, incubated in digestion media for $30 \mathrm{~min}$ at $37^{\circ} \mathrm{C}$, washed twice in cold complete media, and subsequently passed through a $70-\mu \mathrm{m}$ cell strainer to obtain a single-cell suspensions.

Antibodies and flow cytometry. The frequency, phenotype, and function of iNKT cells in PBMC and mononuclear cell suspensions of fetal small intestine, lung, spleen, and MLN were assessed by flow cytometry. All antibodies were obtained from BD Biosciences (Clontech, Palo Alto, CA) unless otherwise indicated. The following antibodies were used to define iNKT cells: CD1d-tetramer loaded with PBS-57 conjugated to phycoerythrin (PE) or allophycocyanin (APC), kindly donated by NIH tetramer resource facility, anti-V $224-\mathrm{PE}$ (clone C15), anti-Vß11-FITC (clone C21), anti-CD3-ECD (clone UCHT1, Beckman Coulter, Atlanta, GA), and in some cases CD45-Alexa-Fluor 700 (Clone HI30, Biolegend, San Diego, CA). B cells and monocytes were excluded from the analyses based on staining with anti-CD14 APC-H7 (Clone M $\varphi$ P9) and anti-CD19 APC-H7 (clone HIB19). Dead cells were excluded from analyses with Live/Dead cell marker-aqua or near-infrared (Invitrogen). To analyze iNKT cell differentiation, the following antibodies were used: anti-CD4 (Clone S3.5 QDot655, Invitrogen. Clone RPA -T4 PE-Cy7/Pacific Blue), anti-CD8 (Clone 3B5 QDot605, Invitrogen), anti-CD161 (Clone DX12 FITC), antiCD45RO (clone UCH1 FITC), anti-CD122 (Clone Mik- $\beta 3$ Biotin, secondary SA-QDot 655, Invitrogen), anti-CD127 (Clone M21 PECy7), anti-CCR7 (Clone TG8 Pacific Blue, Biolegend), anti-CD62L (Clone DREG-56 V450), anti-CD25 (Clone 2A3 PE-Cy7), anti-CD56 (Clone NCAM16.2 PE-Cy7), anti-CD16 (Clone 3G8 Pacific Blue), anti-NKG2A (Clone Z199 PE, Beckman Coulter). Approximately $2 \times 10^{6}$ mononuclear cells were stained in $50 \mu \mathrm{l}$ of fluorescenceactivated cell sorting (FACS) wash buffer $(0.5 \%$ bovine serum albumin, $2 \mathrm{~mm}$ EDTA) for $30 \mathrm{~min}$ on ice. Cells were then washed and subsequently fixed in $2 \%$ paraformaldehyde. All samples were acquired on an LSR II with FACS Diva software (BD) and analyzed with FlowJo software (Treestar, Ashland, OR).

Ex vivo iNKT cell cytokine stimulation. To analyze cytokine expression in iNKT cells, $2 \times 10^{6}$ mononuclear cells were resuspended in $1 \mathrm{ml}$ of complete media alone or containing $1 \mu \mathrm{g} \mathrm{ml}^{-1} \alpha$-GalCer, and incubated at $37^{\circ} \mathrm{C}$ for $8 \mathrm{~h}$, with addition of Brefeldin $\mathrm{A}$ after $2 \mathrm{~h}$. Responses to phorbol myristate acetate/ionomycin were analyzed by incubating $2 \times 10^{6}$ cells in $1 \mathrm{ml}$ of complete medium alone, or containing $2 \mu \mathrm{l}$ Leukocyte Activation Cocktail (phorbol myristate acetate/ionomycin with Brefeldin A, BD Biosciences) overnight at $37^{\circ} \mathrm{C}$. Cells were subsequently washed in complete media, surface stained to identify iNKT cells, fixed with cytofix/cytoperm (BD Biosciences) for $20 \mathrm{~min}$ at $4{ }^{\circ} \mathrm{C}$, washed twice with perm/wash buffer (BD Biosciences), incubated in perm/wash buffer with anti-IFN- $\gamma$ V450 (Clone B27) and anti-TNF- $\alpha$-Alexa Fluor 700 (Clone MAb11) for $30 \mathrm{~min}$ at $4{ }^{\circ} \mathrm{C}$, and finally washed twice in perm/wash buffer before analysis by flow cytometry.

iNKT cell expansion. Mononuclear cell suspensions from the small intestine, spleen, MLN, and adult PBMCs were labeled with $5 \mu \mathrm{M}$ cell trace violet (Invitrogen) in RPMI containing HEPES buffer, L-glutamine and penicillin/streptomycin for $20 \mathrm{~min}$ at $37^{\circ} \mathrm{C}$. The cells were subsequently washed twice in complete medium with $10 \%$ fetal calf serum. After labeling, $4 \times 10^{6}$ cells were cultured in $2 \mathrm{ml}$ of complete media in a 24-well plate, with the addition of $100 \mathrm{ng} \mathrm{ml}^{-1}$ of $\alpha$-GalCer on day 0 . On day $1,50 \mathrm{U} \mathrm{ml}^{-1}$ of IL-2 (Roche, Basel, Switzerland) was added to the culture. The cultures were analyzed after 6-7 days of culture, with addition of fresh media with IL-2 and $\alpha$-GalCer after 3-4 days.

Immunohistochemistry. Small intestinal tissue was fixed overnight at $4{ }^{\circ} \mathrm{C}$ in $4 \%$ electron microscopy grade paraformaldehyde (Electron Microscopy Sciences, Hatfield, PA). The tissue was then dehydrated with ethanol and then xylene before paraffin embedding. Fivemicrometer sections of tissue were de-paraffinized and rehydrated with a decreasing concentration of ethanol. After heat-induced antigen retrieval in citrate buffer and peroxidase blocking with $\mathrm{H}_{2} \mathrm{O}_{2}$, the sections were stained with a 1:1000 dilution of anti-CD1d (clone NOR3.2, AbCam, Cambridge, UK) or isotype-matched control overnight at $4{ }^{\circ} \mathrm{C}$. Slides were then visualized with the EnVision + System-HRP by using 3,3'-diaminobenzidine as a substrate (Dako, Glostrup, Denmark). Images were acquired on a Leica DM6000B using ImagePro version 6 (Leica, Wetzlar, Germany).

Statistical analyses. GraphPad Prism 6 (GraphPad software, San Diego, CA) was used to perform statistical analyses. Statistical comparisons among the different fetal tissue groups were performed using the one-way analysis of variance non-parametric Kruskal-Wallis test, with a confidence level of $95 \%$. A $P<0.05$ value was considered significant. Adult PBMCs were not included in the statistical comparisons.

SUPPLEMENTARY MATERIAL is linked to the online version of the paper at http://www.nature.com/mi

\section{ACKNOWLEDGMENTS}

We thank the San Francisco General Hospital Women's options center for providing tissue samples, and also Advanced Bioscience Resources (ABR) for procuring samples. For technical expertise, Bittoo Kanwar, Rick Dunham, Louise Pontell, Daniel Poole, and Edwin Leeansyah. We thank the AIDS Reagent Tetramer Program for supplying the CD1d-tetramer. L.L. is an Australian National Health and Medical Research Council CJ Martin Postdoctoral Fellow. J.K.S. is a Senior Research Fellow of the Swedish Research Council. J.M. is supported by a grant from the Swedish Research Council.

\section{AUTHOR CONTRIBUTIONS}

L.L. was involved in designing the study, collecting tissue, performing experiments, analyzing data, making figures, and writing the paper. M.I. was involved in collecting tissue and performing experiments. J.M. was involved in making the figures and writing the manuscript. J.K.S. was involved in designing the study and writing the manuscript. D.F.N. was involved in designing the study and writing the manuscript.

\section{DISCLOSURE}

The authors declared no conflict of interest.

c) 2014 Society for Mucosal Immunology 


\section{REFERENCES}

1. Kawano, T. et al. CD1d-restricted and TCR-mediated activation of valpha14 NKT cells by glycosylceramides. Science 278, 1626-1629 (1997).

2. Kinjo, Y. et al. Recognition of bacterial glycosphingolipids by natural killer $T$ cells. Nature 434, 520-525 (2005).

3. Brennan, P.J. et al. Invariant natural killer T cells recognize lipid self antigen induced by microbial danger signals. Nat. Immunol. 12, 1202-1211 (2011).

4. Wieland Brown, L.C. et al. Production of alpha-Galactosylceramide by a Prominent Member of the Human Gut Microbiota. PLoS Biol. 11, e1001610 (2013).

5. Diana, J. \& Lehuen, A. NKT cells: friend or foe during viral infections? Eur. J. Immunol. 39, 3283-3291 (2009).

6. Subleski, J.J., Jiang, Q., Weiss, J.M. \& Wiltrout, R.H. The split personality of NKT cells in malignancy, autoimmune and allergic disorders. Immunotherapy 3, 1167-1184 (2011).

7. Berzins, S.P., Smyth, M.J. \& Baxter, A.G. Presumed guilty: natural killer T cell defects and human disease. Nat. Rev. Immunol. 11, 131-142 (2011).

8. Gapin, L., Matsuda, J.L., Surh, C.D. \& Kronenberg, M. NKT cells derive from double-positive thymocytes that are positively selected by CD1d. Nat. Immunol. 2, 971-978 (2001).

9. Egawa, T. et al. Genetic evidence supporting selection of the Valpha14i NKT cell lineage from double-positive thymocyte precursors. Immunity $\mathbf{2 2}$, 705-716 (2005).

10. Benlagha, K., Wei, D.G., Veiga, J., Teyton, L. \& Bendelac, A. Characterization of the early stages of thymic NKT cell development. J. Exp. Med. 202, 485-492 (2005).

11. Godfrey, D.I., Stankovic, S. \& Baxter, A.G. Raising the NKT cell family. Nat. Immunol. 11, 197-206 (2005).

12. Sandberg, J.K., Stoddart, C.A., Brilot, F., Jordan, K.A. \& Nixon, D.F. Development of innate CD4 + alpha-chain variable gene segment 24 (Valpha24) natural killer T cells in the early human fetal thymus is regulated by IL-7. Proc. Natl Acad. Sci. USA 101, 7058-7063 (2004).

13. Berzins, S.P., Cochrane, A.D., Pellicci, D.G., Smyth, M.J. \& Godfrey, D.I. Limited correlation between human thymus and blood NKT cell content revealed by an ontogeny study of paired tissue samples. Eur. J. Immunol. 35, 1399-1407 (2005).

14. de Lalla, C. et al. Innate-like effector differentiation of human invariant NKT cells driven by IL-7. J. Immunol. 180, 4415-4424 (2008).

15. Beziat, V. et al. Shaping of iNKT cell repertoire after unrelated cord blood transplantation. Clin. Immunol. 135, 364-373 (2010).

16. Sandberg, J.K., Bhardwaj, N. \& Nixon, D.F. Dominant effector memory characteristics, capacity for dynamic adaptive expansion, and sex bias in the innate Valpha24 NKT cell compartment. Eur. J. Immunol. 33, 588-596 (2003).

17. Gumperz, J.E., Miyake, S., Yamamura, T. \& Brenner, M.B. Functionally distinct subsets of CD1d-restricted natural killer T cells revealed by CD1d tetramer staining. J. Exp. Med. 195, 625-636 (2002).

18. Eger, K.A., Sundrud, M.S., Motsinger, A.A., Tseng, M., Van Kaer, L. \& Unutmaz, D. Human natural killer Tcells are heterogeneous in their capacity to reprogram their effector functions. PLoS One 1, e50 (2006).

19. de Lalla, C. et al. Invariant NKT cell reconstitution in pediatric leukemia patients given HLA-haploidentical stem cell transplantation defines distinct $\mathrm{CD} 4+$ and CD4- subset dynamics and correlates with remission state. J. Immunol. 186, 4490-4499 (2011).

20. Olszak, T. et al. Microbial exposure during early life has persistent effects on natural killer T cell function. Science 336, 489-493 (2012).

21. Wingender, G. et al. Intestinal microbes affect phenotypes and functions of invariant natural killer T cells in mice. Gastroenterology 143, 418-428 (2012).

22. Michaelsson, J., Mold, J.E., McCune, J.M. \& Nixon, D.F. Regulation of Tcell responses in the developing human fetus. J. Immunol. 176, 5741-5748 (2006).

23. McNab, F.W. et al. Peripheral NK1.1 NKT cells are mature and functionally distinct from their thymic counterparts. J. Immunol. 179, 6630-6637 (2007).

24. Baev, D.V. et al. Distinct homeostatic requirements of CD4 + and CD4subsets of Valpha24-invariant natural killer T cells in humans. Blood 104, 4150-4156 (2004).

25. Ladd, M. et al. Natural killer T cells constitutively expressing the interleukin2 receptor alpha chain early in life are primed to respond to lower antigenic stimulation. Immunology 131, 289-299 (2010).
26. Boyson, J.E. et al. CD1d and invariant NKT cells at the human maternal-fetal interface. Proc. Natl Acad. Sci. USA 99, 13741-13746 (2002).

27. MacDonald, H.R. NK1.1 + T cell receptor-alpha/beta + cells: new clues to their origin, specificity, and function. J. Exp. Med. 182, 633-638 (1995).

28. Exley, M.A. \& Koziel, M.J. To be or not to be NKT: natural killer T cells in the liver. Hepatology 40, 1033-1040 (2004).

29. van Dieren, J.M. et al. Roles of CD1d-restricted NKT cells in the intestine. Inflamm. Bowel. Dis. 13, 1146-1152 (2007).

30. Nieuwenhuis, E.E. et al. Cd1d-dependent regulation of bacterial colonization in the intestine of mice. J. Clin. Invest. 119, 1241-1250 (2009).

31. Adkins, B., Leclerc, C. \& Marshall-Clarke, S. Neonatal adaptive immunity comes of age. Nat. Rev. Immunol. 4, 553-564 (2004).

32. McDonagh, S., Maidji, E., Ma, W., Chang, H.T., Fisher, S. \& Pereira, L. Viral and bacterial pathogens at the maternal-fetal interface. J. Infect. Dis. 190, 826-834 (2004).

33. Mendz, G.L., Kaakoush, N.O. \& Quinlivan, J.A. Bacterial aetiological agents of intra-amniotic infections and preterm birth in pregnant women. Front. Cell Infection Microbiol. 3, 58 (2013).

34. Kinjo, Y. et al. Invariant natural killer $T$ cells recognize glycolipids from pathogenic Gram-positive bacteria. Nat. Immunol. 12, 966-974 (2011).

35. Bai, L. et al. Natural killer T (NKT)-B-cell interactions promote prolonged antibody responses and long-term memory to pneumococcal capsular polysaccharides. Proc. Natl Acad. Sci. USA 110, 16097-16102 (2013).

36. Schroder, K., Hertzog, P.J., Ravasi, T. \& Hume, D.A. Interferon-gamma: an overview of signals, mechanisms and functions. J. Leukoc. Biol. 75, 163-189 (2004).

37. Rossjohn, J., Pellicci, D.G., Patel, O., Gapin, L. \& Godfrey, D.I. Recognition of CD1d-restricted antigens by natural killer T cells. Nat. Rev. Immunol. 12, 845-857 (2012).

38. McNab, F.W. et al. The influence of CD1d in postselection NKT cell maturation and homeostasis. J. Immunol. 175, 3762-3768 (2005).

39. Sille, F.C. et al. Critical role for invariant chain in CD1d-mediated selection and maturation of Valpha14-invariant NKT cells. Immunol. Lett. 139, 33-41 (2011).

40. Mshvildadze, M., Neu, J., Shuster, J., Theriaque, D., Li, N. \& Mai, V. Intestinal microbial ecology in premature infants assessed with nonculture-based techniques. J. Pediatr. 156, 20-25 (2010).

41. Satokari, R., Gronroos, T., Laitinen, K., Salminen, S. \& Isolauri, E. Bifidobacterium and Lactobacillus DNA in the human placenta. Lett. Appl. Microbiol. 48, 8-12 (2009).

42. Rautava, S., Nanthakumar, N.N., Dubert-Ferrandon, A., Lu, L., Rautava, J. \& Walker, W.A. Breast milk-transforming growth factor-beta(2) specifically attenuates $\mathrm{IL}$-1 beta-induced inflammatory responses in the immature human intestine via an SMAD6- and ERK-dependent mechanism. Neonatology 99, 192-201 (2011).

43. Gordy, L.E. et al. IL-15 regulates homeostasis and terminal maturation of NKT cells. J. Immunol. 187, 6335-6345 (2011).

44. Castillo, E.F., Acero, L.F., Stonier, S.W., Zhou, D. \& Schluns, K.S. Thymic and peripheral microenvironments differentially mediate development and maturation of iNKT cells by IL-15 transpresentation. Blood 116, 2494-2503 (2010).

45. Rosmaraki, E.E., Douagi, I., Roth, C., Colucci, F., Cumano, A. \& Di Santo, J.P. Identification of committed NK cell progenitors in adult murine bone marrow. Eur. J. Immunol. 31, 1900-1909 (2001).

46. Freud, A.G. et al. A human CD34(+) subset resides in lymph nodes and differentiates into CD56bright natural killer cells. Immunity 22, 295-304 (2005).

47. Madrigal-Estebas, L. et al. Human small intestinal epithelial cells secrete interleukin-7 and differentially express two different interleukin-7 mRNA Transcripts: implications for extrathymic T-cell differentiation. Hum. Immunol. 58, 83-90 (1997).

48. Shalapour, S. et al. Commensal microflora and interferon-gamma promote steady-state interleukin-7 production in vivo. Eur. J. Immunol. 40, 2391-2400 (2010).

49. Yang-Snyder, J.A. \& Rothenberg, E.V. Spontaneous expression of interleukin-2 in vivo in specific tissues of young mice. Dev. Immunol. 5, 223-245 (1998). 